\title{
Knowledge and practices surrounding zoonotic disease among Mongolian herding households
}

\author{
Amber N. Barnes 1,2,3* $^{1,}$, Uyanga Baasandavga ${ }^{1,4}$, Anu Davaasuren ${ }^{1,5}$, Battsetseg Gonchigoo ${ }^{1}$ and \\ Gregory C. Gray $2,6,7,8$
}

\begin{abstract}
The strong bond between herder and livestock was forged centuries ago in rural Mongolia and remains an element of national pride and a cornerstone to the economy. However, semi-nomadic herders frequently live at the edge of human health care, veterinary services, and municipal infrastructure like water and sanitation. This study examined zoonotic risk factors and disease perceptions among 150 rural herding households. Less than half of the participating households used an improved drinking water source (43.3\%), and the majority of herding families did not use an improved sanitation service (68.5\%). Almost half of the study population practise open defaecation (49.7\%). Hand washing occurs after animal contact (78\%) but not after defaecation/urination (76.6\%). Domestic animal ownership and/or presence was reported at every household, and exposure risks varied by the gender of the household member. Most households had knowledge about zoonotic disease transmission (74\%) but far less recognized the risk of reverse zoonoses, or human-to-animal disease transmission (53.3\%). Few survey respondents believed that animal contact is a risk factor for diarrhoeal disease (8.7\%). This study highlights zoonotic disease exposure risks from animal husbandry practices and inadequate water, sanitation, and hygiene access and behaviours among rural herding households. Zoonotic disease prevention among Mongolian herders should be implemented using a One Health framework to simultaneously address human, animal, and environmental health concerns of rural herding households.
\end{abstract}

Keywords: One Health, Zoonoses, Herder, Animal husbandry, Sanitation, Hygiene

\section{Introduction}

Throughout Mongolian history, pastoralism has remained the epitome of the nation's identity. In fact, historical records suggest that the early domestication of wild animals and the subsequent spread of livestock first began in this country more than 10,000 years ago (Badarch and Zilinskas 2015; Zinsstag et al. 2016a). Agriculture, in particular herding, drives the Mongolian economy and provides the biggest employment sector for the working population (Odontsetseg et al. 2007;

\footnotetext{
*Correspondence: amber.barnes@unf.edu

${ }^{1}$ Institute of Veterinary Medicine, Ulaanbaatar, Mongolia

2Division of Infectious Diseases, School of Medicine, Duke University,

Durham, NC, USA

Full list of author information is available at the end of the article
}

Altangerel et al. 2011; Ruhlmann 2018; Sack et al. 2018; National Statistical Office of Mongolia 2019). Approximately $26 \%$ of the country's residents are herders (Boldbaatar et al. 2017). Herds commonly consist of sheep, goats, cattle, horses, camels, yaks, and/or reindeer, depending on the region of the country. Livestock generate items such as meat and milk products, leather and hides, and wool, cashmere, and other fibres for household sustenance, barter, and sale (Honeychurch 2010; Batzukh et al. 2012; Zinsstag et al. 2016b; Bayasgalan et al. 2018).

But the role of livestock within Mongolian herding households expands beyond that of income or even food production. The cultural significance associated with 
herding and animal husbandry in Mongolia, coupled with the unique opportunities for close contact due to the isolation of households, the extreme climate and landscape, and the reliance upon animal products for daily dietary needs, may contribute to an increase in exposure risks for zoonoses (Foggin et al. 2000). Animal husbandry has been associated with human infections of diarrhoeal agents such as Cryptosporidium spp., Giardia intestinalis, Campylobacter, Salmonella, and Escherichia coli (Hong et al. 2014; Zambrano et al. 2014). Nomadic herding livestock commonly suffer from co-infections of protozoa, other enteric and ectoparasites, and viral vector-borne disease (Zinsstag et al. 2016c). When animals are sick, they present a health hazard not only to humans but also to their means of revenue (McFadden et al. 2016).

As with other pastoral communities, the herding households of rural Mongolia are semi-nomadic and set up in seasonal camps traversing large swaths of shared steppe and desert pasture (Bedunah and Schmidt 2004). Herds intermingle as they free-range across the steppe and desert and frequently come in contact with wildlife, which may contribute to an increase in livestock zoonotic disease rates (Bedunah and Schmidt 2004; Odontsetseg et al. 2007, 2009; Zinsstag et al. 2016c). Most families live in gers, which are collapsible, round felt tents resembling the western notion of a yurt (Ahearn 2018b). Intensive herding practices over the last several decades coupled with climate change drivers has led to desertification, land degradation, and an increase in natural disasters such as drought, windstorms, heavy snowfall as well as extreme temperature fluctuations (Batzukh et al. 2012; Bedunah and Schmidt 2004; Reid et al. 2014). The increasing necessity of moving livestock to better grazing pastures and water sources throughout the seasons and across larger areas means that herding households of Mongolia are often located far from city centres and other development infrastructure such as running water, municipal power grids, sewage systems, supermarkets, schools, veterinarians and health care facilities (Bold 1996; Benwell 2006; Mocellin and Foggin 2008; Schelling et al. 2016; Sack et al. 2018). The hardships faced by herders has led to a slow and steady rural-to-urban migration of youth in search of more opportunities in education, training, and employment (Batzukh et al. 2012).

The urban-rural divide of Mongolian households illustrates a sharp contrast in access to resources, service availability, and health outcomes (National Statistical Office of Mongolia 2015). A lack of roads and reliable transportation options for household members to reach their district (soum) or even sub-district (bagh) centres within rural provinces (aimags) affects the ability to acquire necessary supplies or assistance. This is especially true during times of the year that require significant hands-on animal husbandry such as during birthing, milking, and shearing seasons or when making preparations for the winter, typically a time for culling herds (Cooper and Gelezhamstin 1994; Bold 1996; Foggin et al. 1997; Mocellin and Foggin 2008; Swiss Agency for Development and Cooperation 2015). During the winter, rural herders can be sequestered for upwards of 6 months with heavy snowfall or extreme weather events ( $d z u d s)$ making travel dangerous. This, in conjunction with poor mobile phone service, prevents sufficient emergency response to disease outbreaks, injuries, and illness in household members or their animals (Mocellin and Foggin 2008; Ahearn 2018b).

A severe decline in the rural veterinary and human health care system coordination during the past couple of decades has resulted in more centralized veterinary establishments that are inaccessible to many pastoralists (Odontsetseg et al. 2007; Mocellin and Foggin 2008; Ruhlmann 2018). The shifting political landscape also gave rise to larger herd sizes and less livestock control, a breakdown in disease surveillance and reporting, a surge in zoonotic and endemic diseases, and cross-border outbreaks (Bedunah and Schmidt 2004; Odontsetseg et al. 2005, 2007; Mocellin and Foggin 2008; Batzukh et al. 2012; Tsend et al. 2014; Dugarova 2019). Many of the circulating zoonotic diseases in Mongolia and neighbouring countries have been classified as priority One Health concerns, or challenges that present concurrent risks to humans, animals, and the environment. Zoonotic diseases of One Health importance in Mongolia include, but are not limited to, anthrax, avian influenza, cysticercosis, brucellosis, trichinellosis, cryptosporidiosis, leptospirosis, dengue fever, echinococcosis, glanders, hemorrhagic fever with renal syndrome, bovine tuberculosis, campylobacteriosis, Japanese encephalitis, listeriosis, malaria, plague, E. coli, rabies, Crimean Congo hemorrhagic fever, tick-borne encephalitis, salmonellosis, toxoplasmosis, Q fever, tularemia, and West Nile fever (Batzukh et al. 2012; McFadden et al. 2016). These diseases may be spread by bites from infected vectors such as ticks, fleas, and mosquitoes; through contact with infected blood and tissue during hunting, butchering, or slaughtering of animals or during birthing and milking seasons; and most commonly by the faecal-oral route via contaminated food, water, hands, and objects. The need for One Health programming is critical to address the multi-faceted risk factors present in Mongolia (Batsukh et al. 2012; Zinsstag et al. 2016b; Ruhlmann 2018).

Since pastoralist communities are often excluded from large health surveys globally, it is difficult to truly assess the current zoonotic disease burden among rural nomadic humans, animals, and their environment (Schelling et al. 2016; Zinsstag et al. 2016c). Still, previous research has 
shown an increased prevalence of zoonotic disease among herder families in Mongolia (Mocellin and Foggin 2008). The aim of this study was to identify zoonotic disease knowledge and practices among Mongolian herding households and ascertain potential opportunities for One Health interventions and disease prevention.

\section{Study area}

Mongolia is a landlocked country with the Russian Federation to the north and the People's Republic of China to the south. The change in geographical zones starting from the north to the south starts with forest (taiga), followed by forest-steppe, steppe (grassland pasture), semi-desert, and desert (Odontsetseg et al. 2007, 2009). Although it encompasses more than $1,500,000 \mathrm{~km}^{2}$, Mongolia is the most sparsely populated country in the world with just over three million people (Honeychurch 2010; World Bank 2019). In contrast, by the end of 2018, there were over 66 million livestock, predominantly throughout the rural areas (National Statistical Office of Mongolia 2019). Data from a 2013-2014 national household survey found that $78 \%$ of the rural households reported owning domestic and/or pet animals compared to $15 \%$ of the urban households (National Statistical Office of Mongolia 2015).

Every province (aimag) is a host to many rural herding households that practise large, labour-intensive animal husbandry operations at the homesite. Each of the 21 aimags has a veterinary service with laboratory diagnostics, typically located in the province's capital city, and 10 of the aimags also house an outpost of the National Center for Zoonotic Disease (Batsukh and Battsetseg
2014). Most residents (over 60\%) live in urban areas, with $41 \%$ living in the capital city of Ulaanbaatar as of 2014 (National Statistical Office of Mongolia 2015). Water and sanitation infrastructure and service utilization is split along the rural-urban divide with approximately $59 \%$ of the rural households using an improved drinking water source and 39\% using an improved sanitation service compared to $74 \%$ and $69 \%$, respectively, of the urban households (National Statistical Office of Mongolia 2015). Open defaecation is common in rural Mongolia, and a previous national survey found a quarter of households engage in this practice (National Statistical Office of Mongolia 2015). Researchers have found unimproved sanitation service utilization, including open defaecation, to be common in peri-urban settings, too (Uddin et al. 2014). The country has a World Bank ranking of lower middle income, and the average life expectancy at birth in 2017 was 69 years (World Bank 2019).

\section{Methods}

\section{Study design}

Within the framework of a larger study looking into the prevalence of zoonotic enteric parasites, a crosssectional survey was administered to 150 herding households to evaluate zoonotic exposure risks, knowledge, and attitudes. Using a convenience sampling strategy, participating households were evenly divided across three rural aimags including Selenge, Zavkhan, and Dundgovi (Fig. 1). These provinces include steppe, forest, grassland, and mountain landscapes. Primary livestock species within these provinces include sheep,

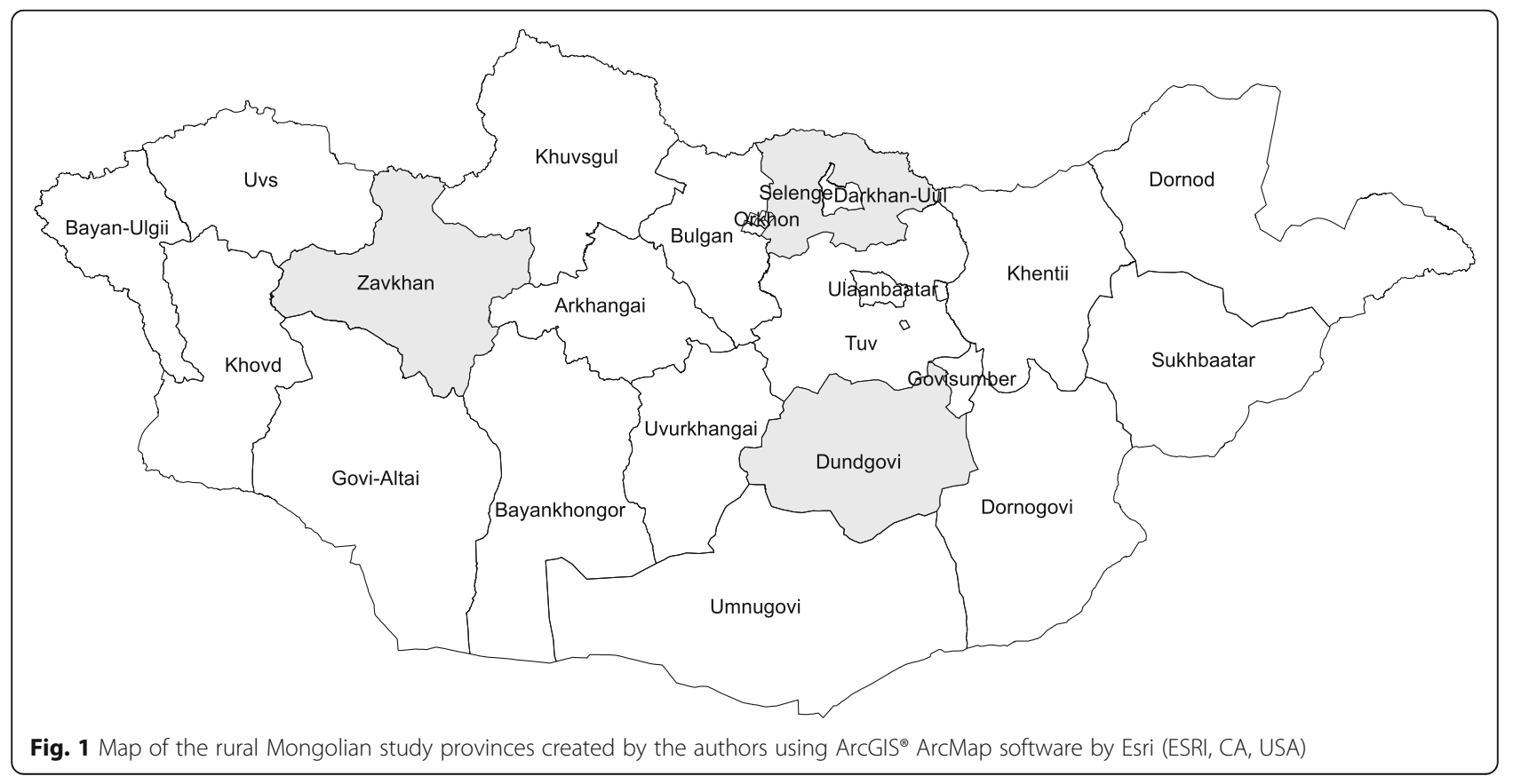


goats, horses, cows, yaks, and camels. Poultry and swine husbandry is uncommon in Mongolia (Odontsetseg et al. 2005).

Soums within each province were first ranked by highest animal density to lowest animal density, according to provincial governmental data. The number of total soums differs by province. However, within the top 25\% of the highest animal density soums for each province, one was selected at random. This resulted in the selection of the following soums: Tsagaannuur in Selenge province, Tosontsengel in Zavkhan province, and Erdenedalai in Dundgovi province. Below the soum level, smaller administrative units are known as baghs. The number of total baghs differs by soum. However, using the same animal density ranking of the baghs within each selected soum, coupled with consultation with local veterinarians on terrain difficulties and accessibility of rural ger households, two bagh locations were chosen as sampling sites within each soum. Household survey collection was evenly divided between the two baghs within each province with half occurring during the spring/summer months of 2017 and the other half during the fall of 2017. Twenty-five households were selected for sampling in each bagh in accordance with time and budget constraints.

Local guides and veterinarians assisted the field team in transecting each bagh area to look for individual gers or khot ails. Khot ail units may be created out of familial ties between the ger households or form due to kinship with members assisting one another with labour and social support while remaining in charge of their own herds and marketable goods (Bold 1996; Benwell 2006; Mocellin and Foggin 2008). When a khot ail was found, all ger households within were invited to participate. Therefore, moving downward in administrative scale, households were selected for participation by their aimag, soum, bagh, and khot ail. At the ger, trained field staff conducted a household survey in Mongolian lasting approximately 20-30 min. Respondents were selfidentified as a head of the household with decisionmaking abilities. The survey contained questions related to household characteristics; water, sanitation, and hygiene (WASH) behaviours; farm and animal husbandry practices; and knowledge on zoonotic disease and their perceived risks.

\section{Statistical analysis}

Using STATA ${ }^{\circ}$ Statistical Software, version 15.1 (Statacorp 2018), and Microsoft ${ }^{\circ}$ Excel, version 16.24 (Microsoft 2019), descriptive statistical tests were used to categorize household demographics, WASH access and behaviours, reported animal contact, the presence of zoonotic risk factors, knowledge and perceptions of zoonoses, and gender roles associated with animal husbandry. Variables related to improved versus unimproved drinking water and sanitation were categorized according to the Joint Monitoring Programme for Water Supply, Sanitation and Hygiene (JMP) (WHO/UNICEF 2019). Improved drinking water sources tend to be safer by design or manufacture and include piped water, boreholes or tubewells, protected springs and dug wells, rainwater collected prior to environmental contamination, and packaged, bottled, or delivered water (WHO/UNICEF 2019). Unimproved water categories include unprotected springs or dug wells and drinking surface water directly (i.e. lake or river water) that are at a higher risk of contamination. A discussion with the WHO/UNICEF Joint Monitoring Programme (JMP) and observational data from the field on the inability of rural households to safely collect and store snow free of environmental and livestock contamination meant that melted snow was considered unimproved for this study population (R. Johnston, personal communication, March 2 , 2019). Improved sanitation systems prevent human contact with excreta and typically include flushing or pour toilets connected to a sewage system, septic tanks and pit latrines, ventilated improved pit latrines, composting or bio-toilets, and pit latrines with concrete slabs (WHO/ UNICEF 2019). Sanitation systems such as pit latrines without slabs, hanging latrines, buckets or containers, and open defaecation are all considered unimproved. Data were assumed to be missing at random due to item nonresponse (De Leeuw et al. 2003). Analyses were conducted using only available data.

\section{Results}

Table 1 outlines the characteristics of the surveyed households. The majority of participants reported that a male was the head of the household (93\%), although most survey respondents were female $(60 \%)$. The mean age of the respondents was 41. Household size was largely between 3 and 5 members (67.3\%), and most had no children under the age of five (64\%). Almost all herding families were living in gers $(98.5 \%)$, and all reported home ownership (100\%). Most households did not have electricity (95.3\%) but instead had a solar-powered generator (95.3\%). Manure, wood, and other biofuels were the predominant source of heating fuel (90.1\%). Goods and assets ranged throughout the homes. However, every household had a bank account (100\%), and almost all respondents reported having a mobile phone for the household (97.3\%) and a television (80.7\%). The majority of households had a car or truck $(58 \%)$ or a motorcycle $(68.7 \%)$ but did not have a refrigerator $(17.4 \%)$, radio $(9.3 \%)$, or computer $(1 \%)$.

Table 2 describes household water, sanitation, and hygiene access and behaviours. Less than half of the households surveyed used an improved drinking water source (43.3\%), such as an individual well, shared well, 
Table 1 Respondent demographics and herding household characteristics $(n=150)$

\begin{tabular}{|c|c|c|c|}
\hline Variable and response & $\begin{array}{l}\text { No. of respondents } \\
n(\%)\end{array}$ & Variable and response & $\begin{array}{l}\text { No. of respondents } \\
n(\%)\end{array}$ \\
\hline Province & & Refrigerator $(n=149)$ & $26(17.4)$ \\
\hline Selenge & $50(33.3)$ & Tractor $(n=149)$ & $2(1.3)$ \\
\hline Dundgovi & $50(33.3)$ & Animal-drawn cart $(n=149)$ & $5(3.4)$ \\
\hline Zavkhan & $50(33.3)$ & Car/truck & $87(58)$ \\
\hline Respondent sex & & Motorcycle & $103(68.7)$ \\
\hline Male & $60(40)$ & Bicycle & $2(1.3)$ \\
\hline Female & $90(60)$ & Radio & $14(9.3)$ \\
\hline Head of household ( $n=132)$ & & Television & $121(80.7)$ \\
\hline Male & $123(93.2)$ & Computer & $1(1)$ \\
\hline Female & $9(6.8)$ & Mobile phone & $146(97.3)$ \\
\hline Age group of respondent & & Bank account & $150(100)$ \\
\hline
\end{tabular}

Table 1 Respondent demographics and herding household characteristics ( $n=150)$ (Continued)
$32(21.3)$

$42(28)$

$36(24)$

$25(16.7)$

$15(10)$

$>60$

$14(9.3)$

$101(67.3)$

$34(22.7)$

$1(0.7)$

$>8$

Household has children aged 5 years or younger

Yes

No

$54(36)$

$96(64)$

Housing type $(n=148)$

Ger $146(98.5)$

House

$2(1.35)$

Apartment

Home ownership $(n=149)$

Yes

No

$0(0)$

Electricity in the household $(n=149)$

Yes

No

$142(95.3)$

Solar-powered generator in the household $(n=149)$

Yes

$142(95.3)$

No

$7(4.7)$

Household's main source of heating fuel

$\begin{array}{ll}\text { Electricity } & 5(3.3) \\ \text { Propane } & 5(3.3) \\ \text { Manure/wood/other biofuels } & 135(90.1) \\ \text { Coal } & 5(3.3)\end{array}$

No. of households with the following self-reported assets: piped water to the property, or shared well access in the soum centre. Twenty-eight percent of households used an unimproved drinking water source. Treatment prior to use was typically done by boiling the water (82\%). Most households did not have a designated hand washing area or sink (62.4\%). Those that did have a hand washing site often went outside to access the area (66.1\%). However, all households with hand washing sites self-reported to have soap available at their location at the time of the survey (100\%). Households' hand washing behaviours fluctuated by event. The majority of respondents reported washing their hands in the morning (93.3\%) and after handling animals (78\%). However, hand washing before cooking, eating, and feeding children was uncommon (38\%, 35.3\%, and $7.4 \%$ respectively). In addition, most households do not wash hands after defaecation and/or urination (76.6\%).

Sanitation services for the herding families were largely unimproved (68.5\%) which included a pit latrine without a slab (20.8\%), a bucket or container (0.7\%), and open defaecation (49.7\%). The most common improved sanitation service in the homes was to bury the waste in a hole (31.5\%). No study household used a flush/pour flush toilet.

Figure 2 provides several examples of the lack of water and hygiene services in the rural households. Panel a depicts a recently slaughtered sheep stored without refrigeration or covering to prevent contamination. Panel b depicts a household's hygiene station near livestock and animal waste. The third panel, c, demonstrates a drinking water source shared between survey households and their livestock.

Table 3 depicts animal contact and household zoonotic risk factors. Herding households reported animal contact (83.2\%) and the use of animal manure and compost (83.2\%). The animal manure primarily served as a fuel for fire at the home (99.2\%). Observational data from the 
Table 2 Mongolian herding household water, sanitation, and hygiene access and behaviours $(n=150)$

\begin{tabular}{ll}
\hline Variable and response & $\begin{array}{l}\text { No. of respondents } \\
n(\%)\end{array}$ \\
\hline
\end{tabular}

\begin{tabular}{ll}
\hline Household's primary source of drinking water & \\
Improved & $65(43.3)$ \\
Individual well & $2(1.3)$ \\
Shared well & $2(1.3)$ \\
Piped water to household/property & $21(14)$ \\
Tanker truck & $0(0)$ \\
Rainwater & $0(0)$ \\
Bottled water & $0(0)$ \\
Shared well in soum centre & $17(11.3)$ \\
Unimproved & $42(28)$ \\
Melted snow & $16(10.7)$ \\
Lake, river, or stream & $49(32.7)$ \\
Other water sources not listed & $43(28.7)$
\end{tabular}

Household water treatment prior to consumption

$\begin{array}{ll}\text { Boil water } & 123(82) \\ \text { Filter water } & 3(2) \\ \text { Drink water directly from source } & 24(16)\end{array}$

Household has a sink/hand washing area $(n=149)$

Yes

$56(37.6)$

No

Location of hand washing site $(n=56)$

$\begin{array}{ll}\text { Inside the home } & 19(33.9) \\ \text { Outside the home } & 37(66.1)\end{array}$

Is there soap available at the hand washing site $(n=55)$

$$
\text { Yes }
$$

No

$0(0)$

\section{Hand washing events}

$\begin{array}{ll}\text { In the morning } & 140(93.3) \\ \text { Yes } & 10(6.7) \\ \text { No } & \\ \text { Before cooking } & 57(38) \\ \text { Yes } & 93(62) \\ \text { No } & \\ \text { Before eating } & 53(35.3) \\ \text { Yes } & 97(64.7) \\ \text { No } & \\ \text { Before feeding children in household }(n=54) & 4(7.4) \\ \text { Yes } & 50(92.6) \\ \text { No } & \\ \text { After bathroom visit } & 35(23.3) \\ \text { Yes } & 115(76.7) \\ \text { No } & \\ \text { After handling animals } & \end{array}$

Table 2 Mongolian herding household water, sanitation, and hygiene access and behaviours $(n=150)$ (Continued)

\begin{tabular}{cl}
\hline Variable and response & $\begin{array}{l}\text { No. of respondents } \\
n(\%)\end{array}$ \\
\hline Yes & $117(78)$ \\
No & $33(22)$ \\
Sanitation service used by household $(\boldsymbol{n}=\mathbf{1 4 9})$ & \\
Improved & $47(31.5)$ \\
Flush/pour flush toilet & $0(0)$ \\
Pit latrine (with slab) & $0(0)$ \\
Composting bio-toilet & $0(0)$ \\
Bury in a hole & $47(31.5)$ \\
Unimproved & $102(68.5)$ \\
Pit latrine (no slab) & $31(20.8)$ \\
Bucket/container & $1(0.7)$ \\
Open defaecation & $74(49.7)$ \\
Other sanitation systems not listed & $3(2)$ \\
\hline
\end{tabular}

researchers acknowledge that fires are central in the ger both for warmth and for cooking meals. All homes reported domestic animal ownership or presence. The majority of homes had a $\operatorname{dog}(\mathrm{s})(88 \%)$, cattle $(80.7 \%)$, a horse(s) (87.3\%), sheep (96\%), and a goat(s) (95.3\%). No home had any chickens. Of the households that reported dog ownership or presence, most self-reported that they removed dog waste from around the homesite (80.2\%).

Diarrhoeal disease in animals had occurred in $68.7 \%$ of the households, and $34.7 \%$ of these households experienced animal death due to the illness. However, only $41.8 \%$ of the households with diarrhoeal disease in animals notified a veterinarian about the illness. Animals are allowed to enter approximately half of the homes, often due to extreme cold weather or an illness/weakness in a juvenile animal.

Figure 3 explains how animal contact and zoonotic exposure risks differed by the gender roles of household members. Males were largely in charge of slaughtering (92.6\%) and butchering (90.7\%) animals at the home. Females were primarily tasked with milking animals $(74.5 \%)$ and cooking the meat and milk products (90.7\%). However, many responsibilities were shared across both sexes. Both male and female household members were responsible for sick animals (56.7\%), herding the animals (80.5\%), feeding the animals (67.1\%), and assisting with animal births (83.9\%).

Table 4 describes household zoonotic knowledge and risk perception. Knowledge about zoonotic disease transmission (animal to human) was widely reported in the households (74\%). But a belief in reverse zoonotic disease transmission (human to animal) was less understood with half of the households (53.3\%) stating they did not think humans can give disease to animals and 


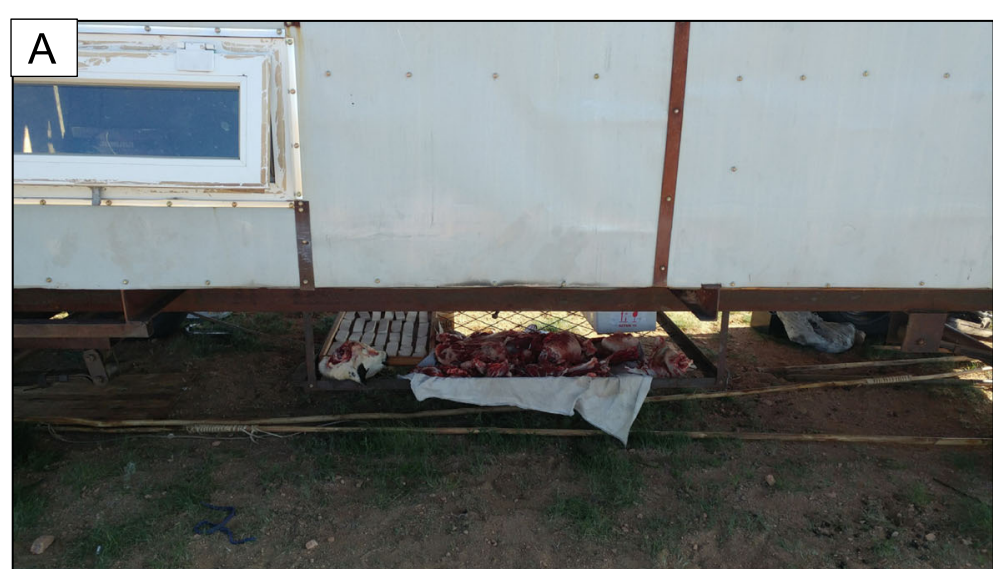

\section{B}
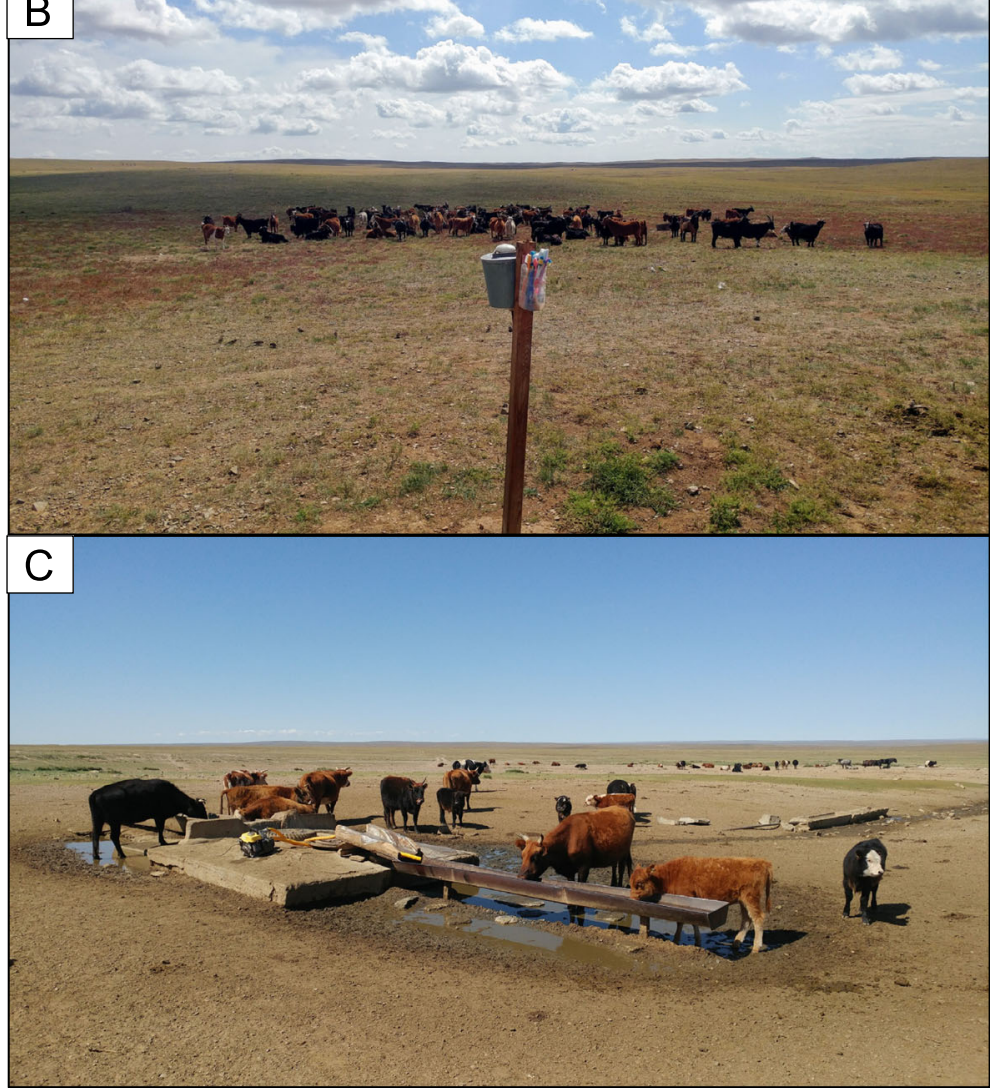

Fig. 2 Photographs of water and hygiene risks at rural herder sampling sites in Dundgovi province were taken by author Amber N. Barnes during field work. A recently slaughtered sheep has been left to dry next to aaruul under a household storage building (a), household toothbrushes and handwashing soap and water are stationed outside next to grazing livestock (b), and a drinking water well is being shared between several households, livestock, and wildlife (c)

many others stating they were unsure of this transmission risk (40\%). Most respondents reported a belief that animal contact can be hazardous to human health (78.7\%), yet the reason for the risk varied between bites and scratches (36\%), ectoparasites (58.7\%), and diseases found in the meat, tissues, and blood of animals (32\%). Only a small percentage of the households believed that a human health risk from animal contact could be diarrhoeal disease $(8.7 \%)$ or that diseases in the animal stool could be a threat to human health (12.7\%). Household recommendations for reducing the risk of zoonotic disease threats to human health included vaccinations of the animal and/or person (57.3\%) and removing animal waste $(42.8 \%)$. Other advice offered by respondents included wearing gloves and washing hands after animal contact. 
Table 3 Animal contact and zoonotic risk factors reported in Mongolian herding households $(n=150)$

\begin{tabular}{|c|c|}
\hline Variable and response & $\begin{array}{l}\text { No. of respondents } \\
n(\%)\end{array}$ \\
\hline \multicolumn{2}{|c|}{ Respondent reported animal contact $(n=143)$} \\
\hline Yes & $119(83.2)$ \\
\hline No & $24(16.8)$ \\
\hline \multicolumn{2}{|c|}{ Household uses compost/animal manure $(n=133)$} \\
\hline Yes & $130(97.7)$ \\
\hline No & $3(2.3)$ \\
\hline \multicolumn{2}{|c|}{ Purpose of compost/animal manure at household $(n=129)$} \\
\hline Fuel for fire & $128(99.2)$ \\
\hline Fertilizer for crops & $1(0.8)$ \\
\hline For building materials & $14(10.9)$ \\
\hline \multicolumn{2}{|c|}{ Domestic animals are owned or present at household } \\
\hline Yes & $150(100)$ \\
\hline No & $0(0)$ \\
\hline \multicolumn{2}{|c|}{ Type of animal(s) reported at household } \\
\hline $\operatorname{Dog}(s)$ & $132(88.0)$ \\
\hline Cat(s) & $15(10.0)$ \\
\hline Chicken(s) & $0(0)$ \\
\hline Cattle & $121(80.7)$ \\
\hline Horse(s) & $131(87.3)$ \\
\hline Sheep & $144(96.0)$ \\
\hline Goat(s) & $143(95.3)$ \\
\hline Camel(s) & $3(2.0)$ \\
\hline Other(s)-yak or hybrid & $35(23.3)$ \\
\hline \multicolumn{2}{|c|}{ Animal waste cleanup in households with dog ownership $(n=132$} \\
\hline Yes & $105(80.2)$ \\
\hline No & $26(19.8)$ \\
\hline \multicolumn{2}{|c|}{ Household animals have had recent diarrhoeal disease } \\
\hline Yes & $103(68.7)$ \\
\hline No & $47(31.3)$ \\
\hline \multicolumn{2}{|c|}{ Households notified a veterinarian for animal diarrhoea $(n=98)$} \\
\hline Yes & $41(41.8)$ \\
\hline No & $57(58.2)$ \\
\hline \multicolumn{2}{|c|}{ Households experienced animal death due to diarrhoea $(n=98)$} \\
\hline Yes & $34(34.7)$ \\
\hline No & $64(65.3)$ \\
\hline \multicolumn{2}{|c|}{ Animals are allowed inside the home $(n=149)$} \\
\hline Yes & $73(49.0)$ \\
\hline No & $76(51.0)$ \\
\hline
\end{tabular}

\section{Discussion}

Within the study population, pastoralism and animal herding was common. Across all provinces, the majority of participating households lived in gers. While easy to transport and set up in new locations conducive to herding, the mobility of this housing structure also means that it is not tied into municipal infrastructure or power grids and the construction design is penetrable by synanthropic rodents and other vectors as well as harsh weather conditions. Gers are typically one building with a shared living, sleeping, cooking, and dining space for multiple family members. Due to the crowded living quarters, infectious diseases can be easily transmitted person-to-person (Lofgren et al. 2007).

As most of the households did not have electricity, the source of fuel for heating the home and for cooking meals was predominantly manure from cattle (argal) or other livestock, wood, or other biofuels. Collection and drying of animal manure for household fuel is common for rural Mongolian herding families (Swiss Agency for Development and Cooperation 2015; Sack et al. 2018; Ahearn 2018b). Animal waste is a known vehicle for multiple zoonotic pathogens, and the extreme Mongolian winter weather makes it hard to achieve the sustained temperature periods necessary to inactivate pathogens for safe handling (Zambrano et al. 2014; Sack et al. 2018). For example, the average temperature from November to February in the winter of 2009-2010 was $-22.05^{\circ} \mathrm{C}\left(-7.69^{\circ} \mathrm{F}\right)$ (Rao et al. 2015). To safely air-dry, manure should be left with daily outdoor temperatures at or above $0^{\circ} \mathrm{C}\left(32^{\circ} \mathrm{F}\right)$ for at least 3 months (Manyi-Loh et al. 2016). Using animal manure for cooking that has not been treated puts household members at risk for faecal-oral transmission of zoonotic diseases (Luna et al. 2018). One way to mitigate this exposure threat would be to wash hands prior to cooking and/or eating as well as after defaecation and urination. However, hand washing in the study households was not widely reported for these key events, despite each being an established method for the prevention of enteric disease (Prüss-Ustün et al. 2014). Hand washing was customary in the morning and after animal contact, the latter of which is an effective zoonotic disease prevention strategy (Zambrano et al. 2014; Ecrumen et al. 2017; Penakalapati et al. 2017).

Most households do not use an improved drinking water source and instead rely on open streams, ponds, and lakes in the environment and the collection and melting of snow. In rural areas, these sources are shared with livestock on the nearby pastures as well as wildlife (Bedunah and Schmidt 2004; Karthe et al. 2017). A 2015 report on population and housing characteristics in Mongolia found that $6.8 \%$ of the rural population used a centralized water supply compared to $51 \%$ of the urban population. The report also found that $89.9 \%$ of the rural households bring their drinking water into the home from outside sources compared to $44.5 \%$ of the urban households (National Statistialc Office of Mongolia 2016). Runoff from animal and human waste can 
Household Member with Primary Responsibility for Animal-Related Activity by Gender

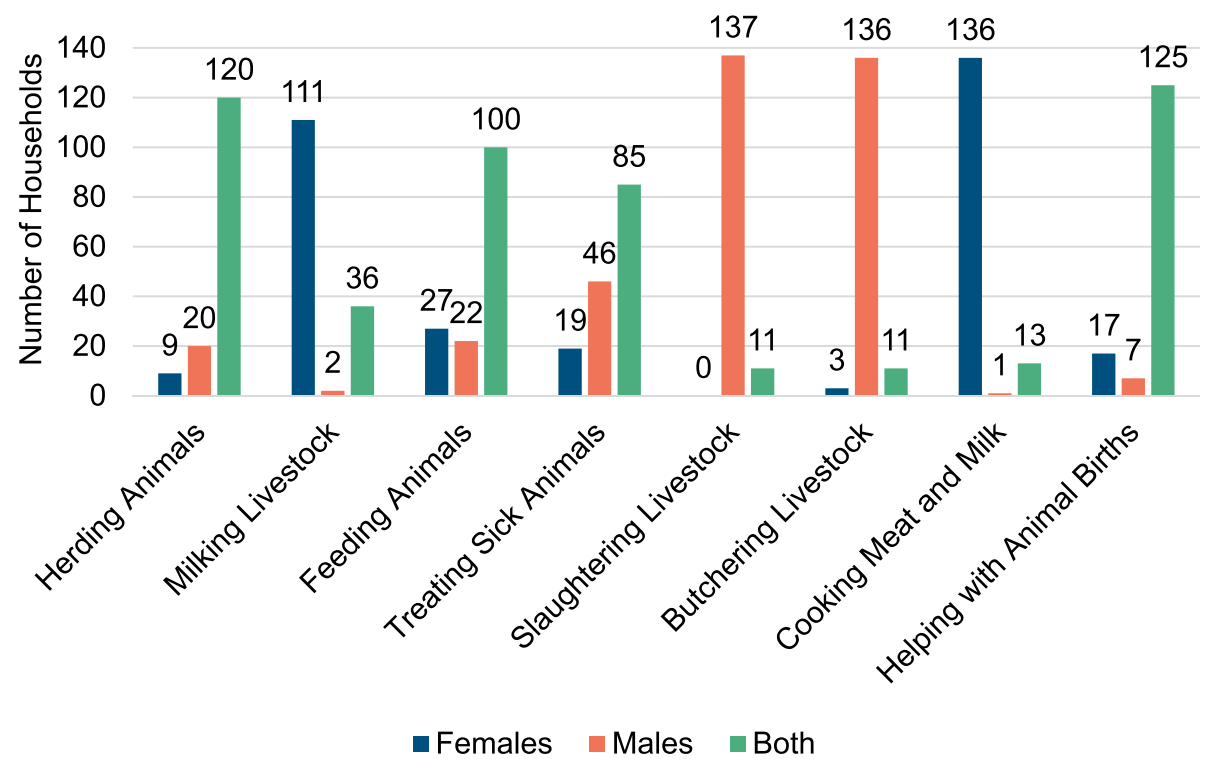

Fig. 3 Gender of the household member with reported responsibilities for animal care among herding families of rural Mongolia

contaminate these water bodies, and industries such as mining and climate change factors such as desertification are reducing accessible water supplies (Hawkins and Seager 2010; Barnes et al. 2017; Schelling et al. 2016; Karthe et al. 2017). Consuming water from an unimproved source can expose a person to many types of infectious agents and even toxic chemical contaminants (Uddin et al. 2014; Prüss-Ustün et al. 2014; Schelling et al. 2016). And while there is insufficient information on overall Mongolian water quality and safety, particularly among rural communities, previous research among herding households found that almost $40 \%$ of those who drank from unimproved water sources did not treat the water prior to use (National Statistical Office of Mongolia 2015; Karthe et al. 2017). Yet, a large portion of the participants in this study reported boiling water prior to use. Unless the water is boiled or treated prior to use each time, stored drinking water can become contaminated at the homesite from domestic animals and vectors, unclean hands and dipping utensils, and the storage container itself (Prüss-Ustün et al. 2014; Uddin et al. 2014; Ecrumen et al. 2017; Barnes et al. 2018).

Indiscriminate human and animal waste can be a major health hazard in rural Mongolia. The households in the current study were principally using unimproved sanitation methods, with almost half practising open defaecation. Previous census data in Mongolia reported that only $7.5 \%$ of the rural households used a waste management service agency and $66.7 \%$ did not have a regular disposal point (National Statistical Office of Mongolia 2016). Comparably, $85.7 \%$ of the urban households in the national census had their waste managed by a service agency and only $6.3 \%$ reported that they did not have a regular place for waste disposal (National Statistical Office of Mongolia 2016). Exposure to human and animal waste in the environment can spread disease and encourage vectors (Zambrano et al. 2014; Penakalapati et al. 2017; Ecrumen et al. 2017). Routine open defaecation and other unimproved sanitation, the inability to wash hands, and the consumption of unimproved drinking water are the trifecta of public health danger surrounding water, sanitation, and hygiene (WASH) services (Prüss-Ustün et al. 2014). In Mongolia, some of the biggest obstacles to better WASH practices and utilization come from unhealthy practices and hygiene customs, negative cultural beliefs surrounding protective behaviours, and poorly designed and accessible infrastructure (UNICEF 2019).

Other hygiene-associated concerns for zoonotic disease exposures among nomadic and pastoral communities involve cultural food preparation techniques and dietary items (Tsend et al. 2014; Barnes et al. 2017). For example, in Mongolia, milk and milk products are produced and consumed daily within herding households such as milk tea, fermented mare's milk (airag), and dried milk curd (aaruul) (Foggin et al. 1997; Foggin et al. 2000; Bamana 2015; Sack et al. 2018). The milking of lactating animals is largely done in the spring/summer, corresponding to the birthing season (Addison and Brown 2014). Nonetheless, home milking and milk consumption remain contributing risk factors for Mongolia's high rates of Brucella (Foggin et al. 1997, 2000; Tsend 
Table 4 Zoonotic knowledge and risk perception reported in Mongolian herding households $(n=150)$

\begin{tabular}{ll}
\hline $\begin{array}{l}\text { Variable and response } \\
\text { Respondent believes animals can give disease or illness to humans } \\
\text { (zoonotic disease transmission) }\end{array}$ \\
Yes & $111(74.0)$ \\
No & $20(13.3)$ \\
Unsure & $19(12.7)$ \\
Respondent believes humans can give disease or illness to animals \\
(reverse zoonotic disease transmission) \\
Yes & $10(6.7)$ \\
No & $80(53.3)$ \\
Unsure & $60(40.0)$ \\
Respondent believes contact with animals presents a human health risk \\
Yes & $118(78.7)$ \\
No & $22(14.7)$ \\
Unsure & $10(6.7)$ \\
Respondent believes that the human health risk comes from the \\
following:
\end{tabular}

${ }^{a}$ Respondents could provide multiple answers for these survey questions

et al. 2014; Bamana 2015; Sack et al. 2018). Brucellosis infection is endemic in Mongolia, and a 2011 national screening of humans and animals found average seropositivity rates of $8 \%$ in herding households and $0.7 \%$ in animals (Myagmar 2014; Bat-Erdene et al. 2019). Brucella can also be transmitted through animal contact with infectious tissue and abortion fluids and by eating contaminated raw meat (Bat-Erdene et al. 2019).

Meat, another staple of traditional Mongolian cuisine, comes from home-slaughtered animals within the rural provinces and can be dried (borts) for long-term storage and consumption throughout the year (Foggin et al. 1997). Direct contact with infected tissue and blood during slaughter and butcher/dressing can expose herders to zoonoses (Odontsetseg et al. 2005, 2007; Tsend et al.
2014; Barnes et al. 2017). In addition, during home slaughtering, the offal from livestock is often fed to dogs, which can then introduce zoonotic disease to an animal with close proximity to the household and to household members (Ito and Budke 2015; Barnes et al. 2017). Echinococcosis is an endemic zoonotic enteric parasite in Mongolia that is often spread through contact with an infected dog who was contaminated through eating viscera of infected livestock (Ito and Budke 2015; McFadden et al. 2016; Barnes et al. 2017). Almost all study households had at least one dog, and field researchers observed many participating households feeding canines the internal organs of livestock. Dogs are also the primary source of human rabies infection in Mongolia and are usually untethered and left to wander (Odontsetseg et al. 2009).

Not only can the disposal of animal remains be an issue for rural areas in the prevention of disease spread, but uncovered food items attract flies, which can carry and transmit zoonotic enteric parasites, as well as synanthropic rodents that can harbour and spread disease (Odontsetseg et al. 2007; Riehm et al. 2011; Penakalapati et al. 2017). Furthermore, preparing food items with unsafe water or on unclean surfaces can lead to water-borne and other enteric disease exposure (Karthe et al. 2017).

Gender roles exist within the pastoralist homes of rural Mongolia but can become blurred when it comes to taking care of the joint herds (Cooper and Gelezhamstin 1994; Swiss Agency for Development and Cooperation 2015). The breakdown of animal care and husbandry responsibility among the study households mirrored that of other research in rural Mongolia (Swiss Agency for Development and Cooperation 2015; Ahearn 2018b). Women were the lead person for milking the animals and for preparing meals for the family. Men were the ones in charge of slaughtering and butchering animals. However, studies have shown that cooperation with herding is common during times of high demand (Cooper and Gelezhamstin 1994; Swiss Agency for Development and Cooperation 2015; Ahearn 2018a). For this study, both genders worked together when a sick animal needed care, to herd the animals, to feed the animals, and when an animal needed assistance with a birth. Livestock birthing season in Mongolia is a high-risk time for exposure to the endemic zoonotic disease of Brucella but may also be helping to spread leptospirosis (Odontsetseg et al. 2005; Bat-Erdene et al. 2019). Leptospires have been associated with the reproductive tract and tissues and abortion fluids of livestock and dogs across the globe, including Mongolia (Odontsetseg et al. 2005; Pires et al. 2018). With each of these behaviours, there is a risk for zoonotic disease transmission. And because animal contact of some kind occurs across all age groups of a herding household, each family member has their own set of unique exposure risks 
(Tsend et al. 2014). Recognizing the target audience at the household for the development of prevention methods against specific zoonotic pathogens or exposure pathways is critical to ensure that the most at-risk population is pursued. For example, messages related to Brucella prevention could be best focused on female herding household members responsible for milking livestock while education on safe slaughter and butchering techniques to prevent echinococcosis may be aimed at male members.

In herding households, all members experience contact with livestock, companion animals, and even wildlife, which can lead to zoonotic and reverse zoonotic disease transmission (Ebright et al. 2003; Odontsetseg et al. 2005; Barnes et al. 2017; Sack et al. 2018). Harsh climates, resource scarcity, and herd competition can also promote malnutrition and lowered immune competence among animals, exposing them to infection, outbreaks, and high mortality rates (Batsukh et al. 2012; Ahearn 2018a). When young animals are ill or malnourished, or at risk for predation or cold weather, they may be brought inside the ger (Foggin et al. 2000). This was also the case for the rural households in this study.

Recognizing household exposure threats can bring about positive behaviour changes aimed at reducing zoonotic disease risk. A baseline knowledge about how zoonoses are spread from animal to animal, animal to human, and in the case of reverse zoonoses, human to animal, is necessary for developing interventions and risk reduction strategies for household members (Odontsetseg et al. 2007). Although most rural herding households reported that they believe animals can cause disease in humans, the opposite direction of transmission was less understood. And even though the overall knowledge on the existence of zoonotic disease was high, beliefs and attitudes regarding how animal contact could pose a specific hazard to public health were lacking. Almost half of the respondents correctly identified ectoparasites (i.e. ticks) as a potential cause of zoonotic disease. Yet, less than $10 \%$ believed that diarrhoeal disease in an animal could be harmful to human health and under 15\% reported that animal stool could present a health threat. This individual knowledge is important as diarrhoeal disease is a recurrent problem in Mongolia, especially during the summer months, and the Ulaanbaatar National Center for Communicable Disease has a hospital unit dedicated to diarrhoeal patients (Ebright et al. 2003). Seasonal zoonotic enteric disease patterns show peaks in spring and summer months that may be associated with food-borne transmission, fly vector density, livestock birthing times, and exposure to faecally contaminated water in the environment (Lal et al. 2012).

Acknowledgement of the zoonotic potential of animal waste is important within the study population as a large majority of households described diarrhoeal illness among their animals with several reporting subsequent mortality. The faecal-oral spread of zoonotic disease is prevalent in areas without access to safe WASH barriers like clean water, hand washing with soap, and the proper disposal of excrement (Ecrumen et al. 2017; Penakalapati et al. 2017; Zambrano et al. 2014). When an outbreak of zoonotic disease is potentially occurring, it is critical to report the event to a local veterinarian or human health care provider so that treatment or control procedures can be administered to stop the spread of infection (Zinsstag et al. 2016c; Barnes et al. 2017). However, less than half of the participating herders notified their veterinarian of the diarrhoeal disease circulating among their animals. Other studies have found that herders often do not notify veterinarians when animal mortality occurs at low levels or when animals are sick, instead preferring to consume the animal and/or sell the skin or fibres (Odontsetseg et al. 2007).

Previous research has demonstrated that effective programming on media channels used by herders and the public health messages conveyed by local veterinarians were successful in educating how to prevent zoonotic disease transmission and motivating positive behaviour change in herding communities (Bayasgalan et al. 2018; Bat-Erdene et al. 2019). With high literacy rates across all groups, written campaigns and educational materials on zoonoses could be combined with other media channels to appeal to herding families (National Statistical Office of Mongolia 2015). Mobile phone accessibility and usage was common within this study population. This is reflected by other surveys in the region and should be explored for reporting zoonotic outbreaks in real time as well as sharing prevention and control strategies with rural herders (Odontsetseg et al. 2007; National Statistical Office of Mongolia 2015; Sack et al. 2018).

High-risk seasonal herding activities, like slaughtering of animals before winter, could serve as key times to spread preventative messages to target populations (Odontsetseg et al. 2007). Setting up One Health awareness and educational campaigns, or epidemiological and veterinary trainings, before the spring work for birthing begins (typically March and April) and before milking season (July and August) may allow for more herder participation (Swiss Agency for Development and Cooperation 2015). Additionally, water supply, collection, and usage decisions in Mongolia do not fall under the typical female gender role category like other pastoral and rural communities across the globe (Hawkins and Seager 2010). Both males and females share at least some decision-making abilities in regard to aspects of household and livestock water usage; therefore, WASH-related enteric zoonotic disease prevention messages should target each gender (Hawkins and Seager 2010; Swiss Agency for Development and Cooperation 2015). 
This study had limitations. Data was self-reported and may not accurately reflect the true risk factors for zoonoses in the participating households. Hand washing was not observed for duration or use of proper methods and therefore may not be adequately serving as a barrier to disease in reporting households. In addition, many rural households participate in multiple types of sanitation services throughout the year, depending upon their seasonal location. For example, although women in the household may use open defaecation while living in the ger during herding activities, she may use a flush toilet if she moves her children into the soum centre during the winter. This is also the case for drinking water sources. For this study, the respondent reported their primary drinking water source or sanitation service. Convenience sampling did not take into consideration the population differences in the aimags, soums, or baghs and instead sampled equal numbers of households within each stratum. Moreover, the convenience sampling of khot ails may have skewed behaviours, attitudes, and disease risk perceptions by families and social networks who may share the same experiences, values, and beliefs. And finally, although the household survey asked the participant to provide advice on what people should do in order to remain safe around animals, we did not ask the households if they engage in each practice. It could be that some of the risk factors we outlined in this paper are mitigated by household practices such as animal vaccinations, the use of gloves, or by wearing masks.

\section{Conclusions}

Rural herding households are faced with many potential zoonotic disease risks from their close contact with livestock, reliance upon animal by-products such as milk and meat, harsh living environment, and lack of accessible water, sanitation, and hygiene services. For Mongolian herders, the health of the land is interconnected to the health of the animals and the rural families it supports. Effective disease prevention and control campaigns will require a coordinated One Health effort to adequately approach the complex challenges within households. Public health messages should be tailored to the audience based on their current knowledge and understanding of zoonotic and reverse zoonotic disease threats, their ability to access information through appropriate communication channels, and their gender roles and household responsibilities surrounding animal contact and care.

\section{Abbreviations}

JMP: Joint Monitoring Programme for Water Supply, Sanitation and Hygiene; UNICEF: United Nations Children's Fund; WASH: Water, sanitation, and hygiene; WHO: World Health Organization

\section{Acknowledgements}

The authors would like to thank the participating herding households for their time. We hope that our findings will support ongoing One Health efforts to improve the well-being of Mongolian families, their livestock, and their environments. We are also grateful to our local drivers, veterinarians, and field guides who worked with us to complete the household surveys across harsh terrain.

\section{Authors' contributions}

Study conception and all field work was conducted by ANB, AD, and UB under guidance and mentorship from BG and GCG. Data entry was done by $A N B, A D$, and UB. ANB analysed the data and drafted the manuscript. All authors read, revised, and approved the final manuscript prior to submission.

\section{Funding}

This study was funded by the National Institutes of Health, Fogarty International Center grant, D43TW009373, "One Health Innovation Fellowships for Zoonotic Disease Research in Mongolia" (GC Gray PI).

\section{Availability of data and materials}

The datasets generated and analysed during the current study are not publicly available due to the personal information collected for participants but are available from the corresponding author on reasonable request and in accordance with the Institutional Review Board of the Duke

University Health System.

\section{Ethics approval and consent to participate}

Approval for this study was granted through the Institutional Review Board of the Duke University Health System (Pro00076868) and the Mongolian Ministry of Health $(\mathrm{MOH})$. Written informed consent was obtained from every household prior to survey administration.

\section{Consent for publication \\ Not applicable.}

\section{Competing interests}

The authors declare that they have no competing interests.

\section{Author details}

${ }^{1}$ Institute of Veterinary Medicine, Ulaanbaatar, Mongolia. ${ }^{2}$ Division of Infectious Diseases, School of Medicine, Duke University, Durham, NC, USA. ${ }^{3}$ Department of Public Health, University of North Florida, Jacksonville, FL, USA. ${ }^{4}$ National Center for Zoonotic Disease, Ulaanbaatar, Mongolia. ${ }^{5}$ National Center for Communicable Disease, Ulaanbaatar, Mongolia. ${ }^{6}$ Duke Global Health Institute, Duke University, Durham, NC, USA. ${ }^{7}$ Global Health Research Institute, Duke-Kunshan University, Kunshan, Jiangsu, China. ${ }^{8}$ Emerging Infectious Diseases Program, Duke-NUS Medical School, Singapore, Singapore.

Received: 5 September 2019 Accepted: 6 February 2020

Published online: 20 April 2020

\section{References}

Addison, Jane, and Brown. 2014. A multi-scaled analysis of the effect of climate, commodity prices and risk on the livelihoods of Mongolian pastoralists. Journal of Arid Environments 109: 54-64.

Ahearn, Ariell. 2018a. Herders and hazards: Covariate dzud risk and the cost of risk management strategies in a Mongolian subdistrict. Natural Hazards 92 (1): $165-181$.

Ahearn, Ariell. 2018b. Winters without women: Social change, split households and gendered labour in rural Mongolia. Gender, Place \& Culture 25 (3): 399-415.

Altangerel, Khukhuu, Badgar Battsetseg, Banzragch Battur, Thillaiampalam Sivakumar, Enkhbaatar Batmagnai, Galsandorj Javkhlan, Bumduuren Tuvshintulga, et al. 2011. The first survey of Theileria orientalis infection in Mongolian cattle. Veterinary Parasitology 182 (2-4): 343-348.

Badarch, Dendevin, and Raymond A. Zilinskas. 2015. Mongolia today: Science, culture, environment and development. London: Routledge.

Bamana, Gaby. 2015. Tea practices in Mongolia: A field of female power and gendered meanings. Asian Ethnology 74 (1): 193. 
Barnes, Amber N., John D. Anderson, Jane Mumma, Zahid Hayat Mahmud, and Oliver Cumming. 2018. The association between domestic animal presence and ownership and household drinking water contamination among periurban communities of Kisumu, Kenya. PLoS One 13 (6): e0197587.

Barnes, Amber N., Anu Davaasuren, Uyanga Baasandagva, and Gregory C. Gray. 2017. A systematic review of zoonotic enteric parasitic diseases among nomadic and pastoral people. PLoS One 12 (11): e0188809.

Bat-Erdene, Delgermaa, Ying-Chih Chuang, and Kun-Yang Chuang. 2019. Brucellosis knowledge and preventive practices among herders in Western Mongolia. Zoonoses and Public Health 66 (1): 133-139.

Batsukh, Zayat, B. Tsolmon, Dashdavaa Otgonbaatar, Baatar Undraa, Adyadorj Dolgorkhand, and Ochirpurev Ariuntuya. 2012. One health in Mongolia. In One Health: The human-animal-environment interfaces in emerging infectious diseases, 123-137. Berlin: Springer.

Batsukh, Zayatiin, and Gonchigoogiin Battsetseg. 2014. One health and biosafetyneed of harmonization in Mongolia. Mongolian Journal of Agricultural Sciences 13 (2): 146-157.

Bayasgalan, Chimedtseren, Tungalag Chultemdorj, Felix Roth, Jakob Zinsstag, Jan Hattendorf, Battsetseg Badmaa, Bayanzul Argamjav, and Esther Schelling. 2018. Risk factors of brucellosis seropositivity in Bactrian camels of Mongolia. BMC Veterinary Research 14 (1): 342.

Bedunah, Donald J., and Sabine M. Schmidt. 2004. Pastoralism and protected area management in Mongolia's Gobi Gurvansaikhan National Park. Development and Change 35 (1): 167-191.

Benwell, Ann Fenger. 2006. Facing gender challenges in post-socialist Mongolia. NIAS press. (pp. 110-139).

Bold, Bat-Ochir. 1996. Socio-economic segmentation-Khot-Ail in nomadic livestock keeping of Mongolia. Nomadic Peoples 39: 69-86.

Boldbaatar, Bazartseren, Rui-Ruo Jiang, Michael E. von Fricken, Sukhbaatar Lkhagvatseren, Pagbajab Nymadawa, Bekhochir Baigalmaa, Ya-Wei Wang, Benjamin D. Anderson, Jia-Fu Jiang, and Gregory C. Gray. 2017. Distribution and molecular characteristics of rickettsiae found in ticks across Central Mongolia. Parasites \& Vectors 10 (1): 61.

Cooper, Louise, and N. Gelezhamstin. 1994. Pastoral production in Mongolia from a gender perspective. RRA Notes 20: 115-123.

De Leeuw, Edith D., Joop J. Hox, and Mark Huisman. 2003. Prevention and treatment of item nonresponse. Journal of Official Statistics 19: 153-176.

Dugarova, Esuna. 2019. Gender, work, and childcare in Kazakhstan, Mongolia, and Russia. Social Policy \& Administration 53 (3): 385-400.

Ebright, John R., Togoo Altantsetseg, and Ravdan Oyungerel. 2003. Emerging infectious diseases in Mongolia. Emerging Infectious Diseases 9 (12): 1509.

Ercumen, Ayse, Amy J. Pickering, Laura H. Kwong, Benjamin F. Arnold, Sarker Masud Parvez, Mahfuja Alam, Debashis Sen, et al. 2017. Animal feces contribute to domestic fecal contamination: Evidence from E. coli measured in water, hands, food, flies, and soil in Bangladesh. Environmental Science \& Technology 51 (15): 8725-8734.

Foggin, Peter M., J. Marc Foggin, and C. Shiirev-Adiya. 2000. Animal and human health among seminomadic herders of central Mongolia: Brucellosis and the bubonic plague in Ovörhangay Aimag. Nomadic Peoples 4(1): 148-168.

Foggin, Peter M., Farkas Otto, S. Shiirev-Adiya, and B. Chinbat. 1997. Health status and risk factors of seminomadic pastoralists in Mongolia: A geographical approach. Social Science \& Medicine 44 (11): 1623-1647.

Hawkins, Roberta, and Joni Seager. 2010. Gender and water in Mongolia. The Professional Geographer 62 (1): 16-31.

Honeychurch, William. 2010. Pastoral nomadic voices: A Mongolian archaeology for the future. World Archaeology 42 (3): 405-417.

Hong, Sung-Hee, Davaasuren Anu, Young-II Jeong, Davaajav Abmed, ShinHyeong Cho, Won-Ja Lee, and Sang-Eun Lee. 2014. Molecular characterization of Giardia duodenalis and Cryptosporidium parvum in fecal samples of individuals in Mongolia. The American Journal of Tropical Medicine and Hygiene 90 (1): 43-47.

Ito, A., and C.M. Budke. 2015. The present situation of echinococcoses in Mongolia. Journal of Helminthology 89 (6): 680-688.

Karthe, Daniel, and K. Westpha. 2017. Water and hygiene in the Kharaa River Basin, Mongolia: Current knowledge and research needs. Geography, Environment, Sustainability 10 (3): 44-53.

Lal, Aparna, Simon Hales, Nigel French, and Michael G. Baker. 2012. Seasonality in human zoonotic enteric diseases: A systematic review. PLoS One 7 (4): e31883.

Lofgren, Eric, Nina H. Fefferman, Yuri N. Naumov, Jack Gorski, and Elena N. Naumova. 2007. Influenza seasonality: Underlying causes and modeling theories. Journal of Virology 81 (11): 5429-5436.
Luna, Sarah, Vikram Krishnasamy, Louise Saw, Lori Smith, Jennifer Wagner, Jenna Weigand, Mackenzie Tewell, et al. 2018. Outbreak of E. coli O157: H7 infections associated with exposure to animal manure in a rural community-Arizona and Utah, June-July 2017. Morbidity and Mortality Weekly Report 67 (23): 659.

Manyi-Loh, Christy, Sampson Mamphweli, Edson Meyer, Golden Makaka, Michael Simon, and Anthony Okoh. 2016. An overview of the control of bacterial pathogens in cattle manure. International Journal of Environmental Research and Public Health 13 (9): 843.

McFadden, A.M.J., P. Muellner, Z. Baljinnyam, D. Vink, and N. Wilson. 2016. Use of multicriteria risk ranking of zoonotic diseases in a developing country: Case study of Mongolia. Zoonoses and Public Health 63 (2): 138-151.

Mocellin, Jérome, and Peter Foggin. 2008. Health status and geographic mobility among semi-nomadic pastoralists in Mongolia. Health \& Place 14 (2): 228-242.

Myagmar, Nansalmaa. 2014. Brucellosis situation in Mongolia and result of bovine brucellosis proficiency test. In The 4th FAO-APHCAVOIE/DLD regional workshop in Thailand Accessible at http://www.fao.org/fileadmin/templates/rap/files/ meetings/2014/140318-cr.mongolia.pdf.

National Statistical Office of Mongolia. 2015. Mongolia: Social Indicator Sample Survey-2013, (Multiple Indicator Cluster Survey, Final Report). Ulaanbaatar, Mongolia. Retrieved from: https://mics-surveysprod.s3.amazonaws.com/ MICS5/East\%20Asia\%20and\%20the\%20Pacific/Mongolia/2013-2014/Final/ Mongolia\%202013-14\%20MICS-SISS_English.pdf.

National Statistical Office of Mongolia. 2016. The 2015 Population and Housing Bycensus of Mongolia: National report. Ulaanbaatar: Accessible at https://www. en.nso.mn/content/166

National Statistical Office of Mongolia. 2019. Mongolian livestock and population data. http://www.en.nso.mn/ . Accessed Aug 2019.

Odontsetseg, Namsraijav, Aaron S. Mweene, and Hiroshi Kida. 2005. Viral and bacterial diseases in livestock in Mongolia. Japanese Journal of Veterinary Research 52 (4): 151-162.

Odontsetseg, Namsraijav, Sh. Tserendorj, Z. Adiyasuren, D. Uuganbayar, and Aaron S. Mweene. 2007. Anthrax in animals and humans in Mongolia. Revue Scientifique et Technique-Office International des Epizooties 26 (3): 701.

Odontsetseg, Namsraijav, D. Uuganbayar, Sh. Tserendorj, and Z. Adiyasuren. 2009. Animal and human rabies in Mongolia. Revue Scientifique et Technique 28 (3): 995.

Penakalapati, Gauthami, Jenna Swarthout, Miranda J. Delahoy, Lydia McAliley, Breanna Wodnik, Karen Levy, and Matthew C. Freeman. 2017. Exposure to animal feces and human health: A systematic review and proposed research priorities. Environmental Science \& Technology 51 (20): 11537-11552.

Pires, Bruno Cabral, Junia Berzin Grapiglia, Lio Moreira, Lauren Hubert Jaeger, Filipe Anibal Carvalho-Costa, and Walter Lilenbaum. 2018. Occurrence of uterine carriers for Leptospira interrogans on slaughtered cows. Microbial Pathogenesis 114: 163-165.

Prüss-Ustün, Annette, Jamie Bartram, Thomas Clasen, John M. Colford Jr., Oliver Cumming, Valerie Curtis, Sophie Bonjour, et al. 2014. Burden of disease from inadequate water, sanitation and hygiene in low-and middle-income settings: A retrospective analysis of data from 145 countries. Tropical Medicine \& International Health 19 (8): 894-905.

Rao, Mukund Palat, Nicole K. Davi, Rosanne D. D’Arrigo, Jerry Skees, Baatarbileg Nachin, Caroline Leland, Bradfield Lyon, Shih-Yu Wang, and Oyunsanaa Byambasuren. 2015. Dzuds, droughts, and livestock mortality in Mongolia. Environmental Research Letters 10 (7): 074012.

Reid, Robin S., María E. Fernández-Giménez, and Kathleen A. Galvin. 2014. Dynamics and resilience of rangelands and pastoral peoples around the globe. Annual Review of. Environment and Resources 39:217-242.

Riehm, Julia M., Damdindorj Tserennorov, Daniel Kiefer, Ingo W. Stuermer, Herbert Tomaso, Lothar Zöller, Dashdavaa Otgonbaatar, and Holger C. Scholz. 2011. Yersinia pestis in small rodents, Mongolia. Emerging Infectious Diseases 17 (7): 1320.

Ruhlmann, Sandrine. 2018. Dealing with highly contagious animal diseases under neoliberal governmentality in Mongolia. Medicine Anthropology Theory 5 (3): 99-129.

Sack, Alexandra, Ulziimaa Daramragchaa, Maitsetseg Chuluunbaatar, Battsetseg Gonchigoo, and Gregory C. Gray. 2018. Potential risk factors for zoonotic disease transmission among Mongolian herder households caring for horses and camels. Pastoralism 8 (1): 2.

Schelling, E., H. Greter, H. Kessely, M.F. Abakar, B.N. Ngandolo, L. Crump, B. Bold, et al. 2016. Human and animal health surveys among pastoralists. Revue Scientifique et Technique-Office International des Épizooties 35 (2): 659-671.

Swiss Agency for Development and Cooperation. 2015. Gender analysis in pastoral livestock herding in Mongolia. https://www.eda.admin.ch/dam/ 
countries/countries-content/mongolia/en/AFS_Gender_Pastoral_2015_ Mongolia.pdf. Accessed Aug 2019.

Tsend, Selenge, Zolzaya Baljinnyam, Bujinlkham Suuri, Enkhbayar Dashbal, Baatarkhuu Oidov, Felix Roth, Jakob Zinstag, Esther Schelling, and Davaalkham Dambadarjaa. 2014. Seroprevalence survey of brucellosis among rural people in Mongolia. Western Pacific Surveillance and Response Journal: WPSAR 5 (4): 13.

Uddin, Sayed Mohammad Nazim, Zifu Li, J.C. Gaillard, Pauley F. Tedoff, HeinzPeter Mang, Jean Lapegue, Elisabeth Maria Huba, Olivia Kummel, and Eric Rheinstein. 2014. Exposure to WASH-borne hazards: A scoping study on periurban Ger areas in Ulaanbaatar, Mongolia. Habitat International 44: 403-411.

UNICEF. 2019. Water, sanitation and hygiene (WASH), UNICEF Mongolia.https:// www.unicef.org/mongolia/water-sanitation-and-hygiene-wash

World Bank. 2019. Mongolia data. https://data.worldbank.org/country/mongolia\#. Accessed Aug 2019

World Health Organization \& United Nations Children's Fund [WHO/UNICEF]. 2019. Monitoring, WHO/UNICEF joint monitoring programme for water supply, sanitation and hygiene (JMP). https://washdata.org/monitoring. Accessed Aug 2019.

Zambrano, Laura D., Karen Levy, Neia P. Menezes, and Matthew C. Freeman. 2014. Human diarrhea infections associated with domestic animal husbandry: A systematic review and meta-analysis. Transactions of the Royal Society of Tropical Medicine and Hygiene 108 (6): 313-325.

Zinsstag, J., M.F. Abakar, M. Ibrahim, R. Tschopp, L. Crump, B. Bonfoh, and E. Schelling. 2016c. Cost-effective control strategies for animal and zoonotic diseases in pastoralist populations. Revue Scientifique et Technique-Office International des Épizooties 35 (2): 673-681.

Zinsstag, J., E. Schelling, B. Bonfoh, L. Crump, and S. Krätli. 2016a. The future of pastoralism: An introduction. Revue Scientifique et Technique-Office International des Epizooties 35 (2): 341-347.

Zinsstag, Jakob, Bassirou Bonfoh, Georges Zinsstag, Crump Lisa, I.O. Alfaroukh, M. F. Abakar, Joldoshbek Kasymbekov, et al. 2016b. A vision for the future of pastoralism. Revue Scientifique et Technique 35: 693-699.

\section{Publisher's Note}

Springer Nature remains neutral with regard to jurisdictional claims in published maps and institutional affiliations.

\section{Submit your manuscript to a SpringerOpen ${ }^{\circ}$ journal and benefit from:}

- Convenient online submission

- Rigorous peer review

- Open access: articles freely available online

High visibility within the field

- Retaining the copyright to your article

Submit your next manuscript at $\boldsymbol{\nabla}$ springeropen.com 